\title{
LA DECADENCIA DE LA ARISTOCRACIA MORISCA: EL CASO DE LOS ÇAFAR DE HUESCA
} Ánchel Conte Cazcarro*

La familia Çafar representa en el panorama oscense del siglo XVI un ejemplo de mentalidad mercantil muy activa, con una economía básicamente especulativa y un enorme movimiento de numerario, rasgos que pueden de finir el capitalismo naciente. Los arrendamientos de rentas nobiliarias y eclesiásticas; los préstamos, la venta de cereal, lana, aceite y azafrán por medio de numerosos representantes y procuradores en una red que se extendía por todo Aragón y fuera de las fronteras del reino; la asociación con sus parientes los Compañero, tan activos o más que ellos, a fin de acrecentar el capital y la capacidad de acción, nos ponen ante un reducido grupo de personas enriquecidas capaces de gozar del favor de las autoridades locales y nacionales, que parecían ignorar su condición de moriscos, incluso después de pasar por la Inquisición en la década de los 50 y ser reconciliados.

El progresivo ascenso de la familia desde mediados de siglo, a tenor de la cada vez más abundante documentación generada, da un giro vertiginoso a partir de los primeros años de la década de los 80, época en que la Inquisición se va a mostrar radicalmente virulenta con una familia (Compañero-Çafar) cuya capacidad económica y de acción los colocaba en el punto de mira de numerosos tiradores: los intransigentes defensores de la ortodoxia tridentina, los resentidos que envidiarían su posición y los asesores reales, siempre a la defensiva frente a la supuesta conspiración de moriscos, turcos y luteranos contra Felipe II, y cuyos efectos más visibles tuvieron lugar en los autos de fe inmediatamente posteriores al año 1580 .

Desde 1580 a 1589, la documentación relacionada con la familia Çafar duplica prácticamente a la conocida de la década anterior y es sensiblemente más numerosa que la de la década siguiente, decayendo de forma muy manifiesta en los comienzos del siglo XVII. Hay en esa evolución un reflejo de la ajetreada vida de la familia, de la delicada situación en la que queda tras

* $\quad$ Catedrático de Historia. IES Sant Josep de Calassanç, Barcelona. 
la intervención de la Inquisición, de la complicada trama de relaciones que se tejen entre el Santo Oficio y los administradores oficiales del patrimonio de los Çafar, y de los numerosos pleitos a los que deben enfrentarse. La escasa información documental del siglo XVII tiene una sencilla explicación: los Çafar habían prácticamente desaparecido y no eran ni una sombra del pasado. Su vasto patrimonio, su intensa actividad, su presencia en la vida social, sus relaciones con todas las esferas de poder del reino habían pasado a mejor vida, y si no generan documentación es, simplemente, porque no quedaba más que un miembro de la familia y en situación económica precaria.

En este trabajo vamos a centrarnos, precisamente, en esos años decisivos que llevan a los Çafar de la gloria a la humillación, de la opulencia a la pobreza. Y dedicaremos especial atención a la figura de dos mujeres que están en el centro de toda la actividad: Esperanza Çafar y su madre María Albariel, mujer de Gabriel Çafar.

Acaso antes de entrar en detalles valdría la pena indicar los hechos más destacados en esos años trascendentales, a fin de que el lector los tenga siempre como punto de referencia, $\mathrm{y}$ conocer a los miembros de la familia con los que vamos a encontrarnos.

\section{LA FAMILIA}

Son cuatro generaciones las que protagonizan estos intensos años: Esperanza Compás y su marido Hernando Çafar; sus hijos Jerónimo (y su mujer y tía segunda Cándida Compañero), Juan, Hernando, José (y sus mujeres Beatriz de Gali -muerta muy pronto- y María Casabona ${ }^{1}$ ), Gabriel (y su mujer María Albariel), y Francisco; los nietos, Juanico (hijo de Jerónimo) y los hijos de Gabriel, Hernando y Esperanza (y su marido Juan Felices menor) y, finalmente, las hijas de éstos, Dorotea, Gracia, Juana y Margarita.

\section{CRONOLOGÍA DE LOS HECHOS MÁS DESTACADOS}

Los hechos más destacados en el período que nos interesan son los siguientes:

1556: Hernando Çafar es elegido jurado de la ciudad.

1558: Hernando Çafar es administrador del trigo de la ciudad. Apresamiento por la Inquisición de Hernando Çafar y su hijo Hernando.

1. Esta es la primera noticia que se da a conocer del segundo matrimonio de José Çafar. 
1559: Hernando Çafar y su hijo son reconciliados en el auto de fe. Apresamiento de Esperanza Compás por la Inquisición.

Testamento cerrado de Hernando Çafar.

1560: Esperanza Compás es reconciliada en el auto de fe.

1562: Testamento de Hernando Çafar.

1563: Hernando Çafar padre tiene franquicias de la ciudad para comerciar.

1566: Hernando Çafar es procurador de la Castellanía de Amposta. 1577: Nuevo testamento cerrado de Hernando Çafar.

Testamento de Esperanza Compás.

Detención por la Inquisición de José Çafar al intentar ir a Argel.

1579: Arrendamiento de las rentas de Antillón, Novales, y Piracés por 4 años y un pago total de 122.000 sueldos.

Arrendamiento de Cuarte, Monflorite y Tramaced.

1580: Operación de arrendamiento con el concejo de Huesca hecha por Jerónimo Çafar, con una garantía de 100.000 sueldos.

Se arriendan rentas en Puibolea por Jerónimo Çafar.

Codicilo de Hernando Çafar que revalida y amplía el testamento cerrado de 1577. Jerónimo Çafar es apresado por la Inquisición.

1581: Testamento de Jerónimo en la prisión de la Aljafería.

Muerte de Jerónimo en prisión.

Muerte de Hernando Çafar en Huesca.

Apresamiento por la Inquisición de María Albariel.

1582: Condena de tres años de cárcel a María Albariel.

Quema en efigie de Jerónimo Çafar.

Se hace inventario de los bienes de Hernando Çafar mayor.

Apresamiento por la Inquisición de Esperanza Compás y de sus hijos Hernando, Gabriel y Francisco.

Codicilo de Esperanza hecho en la cárcel de la Aljafería.

Condena inquisitorial, post mortem, de Hernando Çafar mayor y desenterramiento de sus restos.

Jaime de Aranda es nombrado por la Inquisición administrador de los bienes de los Çafar.

1583: Testamento de Hernando Çafar menor en el cadalso antes de ser ejecutado.

Ejecución de Esperanza Compás y de su hijo Hernando y quema en efigie de Hernando Çafar mayor.

Condenados a galeras Gabriel, José y Francisco Çafar. Testamento de Francisco Çafar en Cartagena antes de entrar en galeras (es su última noticia documentada). 
1585: La Real Audiencia declara herederos de los Çafar a los hermanos Hernando y Esperanza Çafar.

Los libros de cuentas de la casa Çafar son devueltos a la familia.

Nueva comparecencia en un auto de fe de Gabriel Çafar, acusado de fugarse de galeras.

1587: Diversos pleitos de María Albariel por la herencia de los Çafar. Pleito de vecinos de Almudévar contra María Albariel.

1588: Testamento del menor Hernando Çafar renunciando a la herencia en favor de su madre.

Regreso de José Çafar. Vende parte de su patrimonio.

1589: María Albariel recibe de sus hijos lo testado por Hernando Çafar mayor y menor. Enfrentamiento entre Hernando Çafar y su madre, a la que acusa de infamarlo. Capitulaciones matrimoniales de Esperanza Çafar y el cristiano viejo Juan Felices menor.

Esperanza Compás, menor de 14 años, da a su hermano una comanda de 120.000 sueldos.

Venta de un granero, un corral y una bodega olearia por $16.000 \mathrm{~s}$. hecha por M. Albariel, Esperanza Çafar y Juan Felices.

Regreso de galeras de Gabriel Çafar.

Pleito de Cándida Compañero (madre de Juanico, heredero de los Çafar, muerto prematuramente) contra su cuñada María Albariel a causa de la herencia de los Çafar.

Pleito entre María Albariel y José Çafar por la herencia. Venta de casas en Zaragoza hecha por M. ${ }^{\mathrm{a}}$ Albariel.

1590: Entrega a la Inquisición de los libros de cuentas de los Çafar. Venta hecha por Albariel de un albarán por valor de 8.000 s. Testamento de Ana Baraiz, madre de Juan Felices menor. Esperanza Çafar y Juan Felices dan a María Albariel y Gabriel Çafar casas en Zaragoza, y un total de 12.000 sueldos, según obligaban las capitulaciones matrimoniales.

Diversas ventas de casas y tiendas hechas por Esperanza y Juan Felices.

1592: Pleito de Enrique Compañero contra Albariel, Esperanza y Felices por la venta del granero, que según la Real Audiencia le pertenecía a él.

Pleito de Miguel de Mendoza (fianza de Albariel y Felices en la venta del granero) por sentirse estafado.

Encarcelamiento de Juan Felices por deudas.

1593: Felices, Esperanza y M. ${ }^{a}$ Albariel se ven obligados a tomar diversos préstamos. Juan Felices está preso en Zaragoza. 
Incautación de bienes de los Çafar por la Real Audiencia. Pleito de Juan Gómez contra Albariel, Felices y Esperanza.

1594: Juan Compañero reclama a M. ${ }^{a}$ Albariel ocho albaranes, que Jerónimo Çafar se quedó, por valor de 1.334 libras.

Hernando Çafar recibe de su hermana 30.000 s., que es parte de lo acordado en las capitulaciones matrimoniales.

Renuncia de Hernando a cualquier reclamación sobre las herencias de los Çafar. Testamento de Juan Felices mayor.

1595: Felices y Esperanza piden diversos préstamos.

1597: Pleito de Miguel de Mendoza contra su primo Juan Felices por el dinero que le prestó para sacarlo de la cárcel.

1601: Testamento de Juan Felices mayor.

1603: Incautación de un campo de los Çafar.

1606: Testamento de Juan Felices menor. Muerte de Juan Felices menor.

Deudas de Esperanza Çafar e imposibilidad de pagarlas.

Venta de patrimonio por Esperanza Çafar.

1607: Inventario de los bienes de Juan Felices menor.

Pleito entre Esperanza y los tutores de sus hijas y varios vecinos de Almudévar por una deuda.

Esperanza arrienda un huerto.

1608: Esperanza vende casas, corrales, huertos y otros bienes para hacer frente a diversas deudas.

1609: Continúan las ventas por la misma razón.

1610: M. ${ }^{\mathrm{a}}$ Albariel toma en arriendo el trinquete de la ciudad.

1611: Expulsión de los moriscos.

1612: Esperanza Çafar es apresada por la Inquisición y reconciliada tras pagar una multa de 50 ducados de oro.

\section{LOS MOMENTOS DE ESPLENDOR}

La intensa actividad económica y el alto nivel de vida de los Çafar antes de la intervención violenta del Santo Oficio, queda de manifiesto en las abundantes escrituras que hacen referencia a los arriendos de rentas eclesiásticas y nobiliarias en diversos lugares del Altoaragón que les permiten acumular enormes cantidades de cereal y en menor medida de aceite, lana, vino y azafrán, con los que llevarán a cabo un intenso comercio desde Huesca y también desde otros lugares de almacenaje, especialmente Peralta, donde tenían un silo de considerables dimensiones, y desde algunos de los lugares 
que tenían arrendados, como Argavieso, y otros en los que tenían inversiones destacadas, como Almudévar. No se trata ahora de repetir lo ya explicado en otros trabajos al respecto, pero, aun pasándolo por alto, sí vale la pena fijarnos en los datos que respecto a las finanzas y al nivel de vida de la familia nos da el inventario mandado hacer por el Santo Oficio, tras la muerte de Jerónimo Çafar y de Hernando Çafar mayor, al comisario inquisitorial Tomás Cortés y al administrador Jaime de Aranda. El inventario, elaborado entre los meses de febrero y septiembre de 1582, es una prolija relación de lo contenido en la casa (muebles, menaje, armas, joyas, elementos decorativos, ropas...), que nos da a conocer también los libros de cuentas que se hallaban en el estudio de la vivienda y el cereal y otros productos almacenados en los distintos graneros y casas de varios pueblos de la comarca.

La relación de ropas, muchas de ellas telas de lujo importadas, con bordados en oro, aljófar y azabache, por ejemplo; candelabros, vajillas de plata, joyas personales, sombreros de mujer y de hombre, abundantísimas ropas de cama, alfombras, colchas, monedas de oro, etc., nos denuncian el tren de vida de la familia. La interminable relación de joyas y piezas de oro, plata, perlas, granates, con el peso (y en algunos casos las iniciales de sus antiguos dueños), acumuladas en una sola sala podría tratarse del fondo de la caja de empeños que con toda seguridad tuvieron los Çafar ${ }^{2}$. Algunas de estas joyas aún estarán controladas por la familia años después, pero nunca más se da una relación de estas características, como mucho se hace mención a algunas joyas concretas o, de manera más vaga, a las numerosas joyas y monedas de oro que tenía la familia ${ }^{3}$.

Por si esto fuera poco, el inventario nos detalla más de ciento cincuenta albaranes por valor de unas 13.000 libras y el título de treinta y seis libros de contabilidad referentes, esencialmente, a la década de los 70 y a los años 1580 y 1581 , que recogen las actividades económicas de la familia en Huesca y en diversos lugares: Argavieso, Castillón (Castejón del Puente), Permisán, Abiego, Alerre, Novales, Almudévar y Puibolea. Cierran el inventario de cincuenta y cinco hojas las reservas de cereal en diversos graneros en los pue-

2. Se enumeran, con su peso, hasta setenta joyas y piezas de orfebrería de oro, plata, plata sobredorada, acero, marfil y algunas piedras preciosas, como granates y diamantes, y abundantes perlas. Se mencionan también "granos" y monedas de oro: veintiocho monedas de 10 ducados, ocho doblones y cuatro escudos, además de dieciséis reales de plata. Hay que aclarar que "grano" es la unidad de peso mínima en el sistema métrico aragonés, y juntamente con el arienzo son habituales al hablar de metales preciosos. No deja de ser curioso que entre tanta riqueza y lujo no se mencione ni un solo libro, pero sí un lienzo con desnudos femeninos.

3. En 1585, María Albariel recibe del administrador de los bienes familiares puesto por la Inquisición 54 cabos de oro, un salero de plata de tres piezas y tres tazas de plata. En un codicilo hecho en la cárcel inquisitorial por Esperanza Compás se mencionan, sin especificar, plata, ducados de oro y otras monedas. 
blos en los que actúan, como Peralta, Sesa, Arbaniés, Argavieso, Ibieca, Puibolea, Liesa, Albero (donde además del cereal hay madera) y Piracés. En aquellos momentos había almacenados unos 3.800 cahíces de trigo, centeno, avena y ordio (algo más de $530.000 \mathrm{~kg})^{4}$, la mayoría en Argavieso y Peralta. Por la fecha en que se toma nota del cereal (septiembre), hay que pensar que es lo recolectado en la última campaña, y por la misma razón no se anotan reservas de vino, azafrán y aceite, aún sin cosechar, pero que sabemos por los libros de cuentas de años posteriores que también se cultivaban y se comercializaban.

Por referencias posteriores (1585) sabemos que el 21 de enero de 1582, según un inventario del que no queda huella, se encontraron en las casas de Huesca y en los distintos graneros de los Çafar 4.182 cahíces de trigo, 1.451 de centeno, 1.303 de ordio y 794 de avena; 44 nietros (algo más de 7.000 litros) de vino; 3 libras y 9 onzas de azafrán; 58 arrobas de lana, y dinero por valor de 31.424 libras $^{5}$. También había documentos que suponían unas deudas contraídas con los Çafar por valor de 1.407 cahíces de cereal y 359 libras en dinero, más 9 libras en Cuarte. La cantidad de cereal acumulado suponía, una vez comercializado, una fortuna, si tenemos en consideración los libros de cuentas de la familia, en los que se refleja que el precio medio aproximado de un cahíz de cereal rondaba entre las cuatro libras y las cuatro libras y un tercio, según la época del año y el mercado de venta. A todo ello habría que añadir alrededor de una decena de casas, un buen número de tiendas, corrales, graneros y tierras de cultivo, en Huesca; y, también, casas en Zaragoza, además de los bienes en Peraltilla: casas, corrales y graneros. Es muy probable que tuvieran bienes en Alerre, lugar en el que se hacen varios documentos de la familia, y en algunos de los pueblos en que tenían los graneros.

En medio de esta riqueza, la familia Çafar, con los patriarcas Hernando y Esperanza Compás, sus hijos Jerónimo, Hernando, Gabriel, José y Francisco (su otro hijo, Juan, vivía en Argel), y sus nietos pequeños, Juanico, hijo de Jerónimo, y Hernando, Esperanza y Brianda (ésta muerta muy pronto), hijos de Gabriel, podían llevar una vida plácida y gozaban de un prestigio social que no había manchado el hecho de haber pasado, en 1558-1559, por el tribunal de la Inquisición de Zaragoza Hernando y su mujer Esperanza y el segundo de sus hijos, Hernando. Posiblemente, las sospechas sobre su fidelidad al Islam no desaparecieron, pero el dinero permite superar numerosas barreras, y eso se ve en las relaciones mantenidas con todas las esferas de poder: con los miembros de la nobleza de la zona, a quienes arrendaban sus rentas, incluido el Gobernador General de Aragón; con el clero

\footnotetext{
4. El cahíz aragonés equivale a $140 \mathrm{~kg}$.

5. La libra es moneda de cuenta, equivalente a 10 sueldos.
} 
más notorio, como el castellán de Amposta, del que Hernando Çafar mayor fue procurador, o con el gobierno municipal, que concedió amplias franquicias para comerciar en y desde la ciudad, y del que formó parte Hernando Çafar en 1556-1557 como jurado y el año siguiente como responsable del trigo.

El prestigio y poder de la familia y su capacidad de acción queda patente en la azarosa huida de galeras de Gabriel Çafar, su paso por Zaragoza y su viaje a Roma para solicitar una conmutación de su pena a galeras, consiguiendo que su solicitud llegara hasta el Inquisidor General, aunque sin éxito. De regreso de Roma fue a Madrid, donde lo detuvo el Santo Oficio. Es imposible imaginarse esta rocambolesca historia sin contar con la colaboración de la comunidad morisca y de cristianos muy bien situados económica y políticamente. No cabe duda de que los Çafar se movían en ambientes muy cercanos al poder. Incluso en momentos ya de crisis, en 1589, vemos actuar a Juan Felices como procurador del vizconde de Éboli, señor de Albero, Vicién y Fraella.

\section{EL ACOSO INQUISITORIAL}

Desde 1558 y 1559, en que son apresados Hernando Çafar, padre e hijo, y Esperanza Compás, liberados muy pronto tras pagar una pequeña multa de 500 sueldos, aparentemente nada había inquietado a la familia, pero el apresamiento en 1580 de varios miembros de los Compañero conllevó el de Jerónimo Çafar, y desde ese momento, en verano de 1580, hasta 1583, en que son ejecutados Esperanza Compás y su hijo Hernando, la tragedia sobrevuela de manera ininterrumpida sobre los Çafar. Son años en que su situación económica, posiblemente, no se vio definitivamente dañada, pero desde el punto de vista humano dejó un panorama desolador. La pretensión de la Inquisición de descabezar la posible revuelta de los moriscos supuso el acoso y derribo de la familia más significativa, los Çafar-Compañero, y de algunas muy próximas, como los Albariel ${ }^{6}$.

Desde 1580 a 1583 murieron Hernando Çafar mayor y su heredero Jerónimo, el primero por enfermedad en Huesca, y el segundo en la cárcel de la Inquisición, ambos posteriormente quemados en efigie; fueron quemados vivos Hernando Çafar menor y su madre, y fueron condenados a cinco años en galeras los restantes varones residentes en Aragón, Gabriel, José y

6. La obra que mejor detalla la relación de la Inquisición con los moriscos aragoneses en los años que estamos estudiando es la de la doctora Pilar SÁNCHEZ LÓPEZ: Organización y Jurisdicción Inquisitorial: El tribunal de Zaragoza, 7568-1646, Barcelona, Universidad Autónoma de Barcelona, 1989. 
Francisco, éste último posiblemente fallecido en Cartagena antes de embarcar. A todos ellos habría que añadir a María Albariel, condenada a tres años de prisión. Sólo se salva un miembro de la familia, Juan, residente en Argel y a quien la generosidad de los testamentos de sus padres $y$ de su hermano Hernando no pudo convencer de que regresara ${ }^{7}$, y que en tierras africanas se convierte en un punto de referencia para numerosos moriscos aragoneses, tanto en su casa de Argel, a la que acudieron con frecuencia, como en sus visitas clandestinas a España, según se desprende de las declaraciones de varios conversos en los interrogatorios de la Inquisición. Es, sin duda, un elemento clave en el posible intento de sublevación del que se acusaba a los moriscos aragoneses.

Los distintos testamentos hechos por los miembros de la familia, algunos de ellos en la cárcel de la Aljafería y otro, el de Hernando menor, ya en el cadalso, dejan como herederos universales, sucesivamente, a Jerónimo, a Hernando y a Juanico, hijo de Jerónimo. Al resto de los varones y mujeres de la familia se les dejan bienes muebles e inmuebles que no son sino una pequeña parte de la riqueza familiar. Se ve claramente en todos los testamentos de los herederos la voluntad clara de evitar la desintegración del patrimonio familiar, que había de recaer finalmente en Juanico, hijo de Jerónimo y de Cándida Compañero ${ }^{8}$. Pero la prematura muerte del muchacho, sin testar, hará que la herencia vaya a parar a los hijos de Hernando menor, Hernandico y Esperancica (Briandica, la menor, ya había muerto); ambos eran muy chicos, dos niños que se encontraban con una inmensa fortuna, en aquel momento bajo la administración de Jaime de Aranda, a quien el hecho de cuidarse de los bienes de moriscos condenados por la Inquisición le supuso algún insulto y malos tratos por parte de cristianos viejos, lo que obligó al Santo Oficio a intervenir en su favor? .

Llama la atención que no se dictase sentencia de incautación de bienes, pero tampoco es muy seguro que quedase en poder de la familia todo el patrimonio. De los años inmediatamente posteriores a las condenas inquisitoriales hay algún dato económico que nos demuestra que el comercio de la

7. En los testamentos y codicilos de Hernando Çafar mayor de 1559, 1562, 1577 (éste fue el definitivo, aunque modificado por un codicilo en 1580), de Esperanza Compás de 1577 y de Hernando Çafar menor (1583) se deja dinero a Juan si regresa a Aragón y vive como cristiano. Se tiene noticia de otro testamento cerrado de Esperanza posterior al citado, pero no se ha encontrado, aunque se sabe que fue abierto a los pocos días de ser quemada.

8. Los testamentos de Hernando Çafar y los de su mujer siempre reconocían como heredero universal a Jerónimo, si bien todos los hijos recibían bienes y dinero. En el testamento de Jerónimo y en el de su hermano Hernando quedaba como heredero universal Juanico, quien en aquel momento, según los testamentos, residía con su madre fuera del reino.

9. En un documento de 1582, los inquisidores de Aragón dicen que el administrador Aranda fue puesto por la Inquisición para cuidar de los bienes inventariados por el Santo Oficio, y exige que se le respete y no sea vejado, so pena de excomunión. 
casa continuó siendo activo, como manifiestan los libros de cuentas devueltos a la familia por Jaime de Aranda en 1585, al poco de reconocer la Audiencia Real de Aragón como herederos de los Çafar a Hernando y Esperanza, bajo la tutela de su madre María Albariel, que también en 1582 pasó por la Inquisición. El administrador entrega las cuentas de los años 82, 83 y 84, en las que vemos cómo se continuaba comerciando con cereal, lana, aceite, vino y azafrán, esencialmente. Es muy probable que Aranda ofreciese resistencia a la devolución de los libros de cuentas, pero se conserva una sentencia arbitral de julio de 1585 en que se le dice taxativamente que debe devolver a los Çafar todos los bienes y rentas, además de rendir cuentas de los negocios efectuados durante el tiempo que tuvo la administración.

El monto de los negocios realizados en estos tres años es de 22.800 libras, aproximadamente, cantidad, teniendo en cuenta que hace referencia a tres años, inferior a lo que se llevaba a cabo antes del ataque inquisitorial. Por otro lado, no sabemos las cuentas que había pendientes de pago, pero documentos posteriores nos demostrarán que muchos se aprovecharon de la situación familiar para evitar satisfacer las deudas, que aún en los últimos años del siglo estaban pendientes de cobro; y por la misma razón, también los Çafar intentaron no cumplir con sus obligaciones, y así se darán abundantes pleitos y reclamaciones por parte de algunos acreedores, entre los que están colectivos, como un grupo de hombres de Almudévar, y miembros de la familia, como Cándida Compañero y José Çafar, y Juan y Enrique Compañero, que reclaman bienes propios que los Çafar se quedaron, aprovechándose de que los documentos estaban en su archivo, como administradores, y procuradores que eran de los intereses de los Compañero en las tierras de la comarca de Huesca.

Antes se decía que aparentemente no hubo incautación de bienes, pero lo cierto es que hasta la sentencia de la Real Audiencia reconociendo el derecho de los hermanos Hernando y Esperanza a heredar, no está demasiado claro qué ocurrió. Según los documentos de nombramiento de administrador a favor de Aranda ${ }^{10}$, éste debía rendir cuentas a María Albariel anual-

10. La primera noticia que tenemos de que Aranda está al cargo de los bienes de los Çafar es el codicilo hecho por Esperanza Compás en la cárcel de la Inquisición en agosto de 1582, en que reconoce que Jaime de Aranda tiene encomendadas las joyas de la familia, que las deja en herencia a Hernando y Francisco. Es probable que al ser detenidos todos los miembros de la familia, el nombramiento lo hiciese el Santo Oficio, quien nombró también dos "confrares" para hacer el inventario de la familia juntamente con el canónigo de Huesca Tomás Cortés. Hernando Çafar menor, en su testamento redactado en el cadalso, también reconoce a Aranda como administrador, y lo mismo ocurre con un documento firmado por Gabriel, José y Francisco poco antes de ser enviados a galeras, estos últimos documentos son de 1583. En el otoño de 1585, el administrador es el mercader oscense Juan Gómez, y aunque no se hace constar, es muy probable que también fuese impuesto por el Santo Oficio. 
mente, pero no lo hizo sino cuando la sentencia citada le obligó a devolver los libros a los Çafar, acaso porque antes María estaba encarcelada. Sí tenemos constancia de que en 1583 entrega dinero a José, Gabriel y Francisco Çafar estando presos en la Aljafería, concretamente algo más de 19.000 sueldos que, según declara, es una parte de lo que debe dar de los bienes de los Çafar. En el documento no queda claro si ese dinero procede de las rentas y negocios familiares o de la venta de patrimonio, posibilidad ésta que no debe descartarse totalmente.

Tampoco está muy claro qué pasa después con el patrimonio y los negocios de los Çafar, pero da la impresión de que se entra en un período de franca decadencia, como luego veremos. Este ocaso podría haberse iniciado definitivamente con las reclamaciones de los Compañero, alguna venta ilícita protagonizada por los Çafar y por la intervención de la Inquisición, que vuelve a reclamar los libros de cuentas en 1590, y ahora parece que ya de manera definitiva.

Cuando en 1585 María Albariel sale de la cárcel, todos los varones de la casa habían muerto o estaban en galeras, y el heredero Juanico había muerto, lo que la obligó a tomar un papel protagonista. María, originaria de Zaragoza, se nos revelará como una mujer dispuesta a defender a ultranza los derechos de sus hijos y el patrimonio familiar, que actuará frecuentemente haciendo o recibiendo comandas y tejiendo una trama para asegurar la continuidad de la riqueza familiar casando a su hija Esperanza con Juan Felices menor, un infanzón de escasa fortuna ${ }^{11}$, a fin de poner el patrimonio en manos cristianas, para lo que hubo de convencer a su hijo Hernando, a quien en buena lógica debía ir a parar la herencia familiar, de que renunciase a sus derechos, primero haciéndola a ella heredera (1588), y luego asegurándole en las capitulaciones matrimoniales de su hermana (1589) 30.000 sueldos. Sin embargo, la relación entre madre e hijo fue tensa, y hubo una sonada ruptura cuando Herrando le retiró la procuración que le había dado por haberlo infamado, todo al poco de haberla hecho su heredera.

Hasta el momento del matrimonio de su hija, todos los asuntos de la familia quedan a cargo de María Albariel, tanto como representante de su marido por documento emitido en la prisión, como por ser tutora de los herede-

11. La familia Felices pertenece a la pequeña nobleza local. El padre de Juan, del mismo nombre, ocupó en varias ocasiones el cargo de justicia de la ciudad, y entre los miembros de la familia los hay canónigos de la Seo y beneficiados de San Pedro el Viejo. El matrimonio Juan Felices y Ana Baraiz tuvieron ocho hijos. Tras la muerte de la madre (1590), el último testamento conocido del padre (1601) dejaba como heredera universal a su hija Ana. En este testamento se hace constar que se transmiten también los bienes procedentes de Luis Felices, hermano del testante, y los de María de Baraiz. Aparte de los bienes en Huesca, que no se especifican, y otros en Los Molinos (casas, casales, eras, huertos, campos, posesiones y bienes sitios), se hace transmisión de dinero, y ninguna cantidad es realmente elevada, sólo los 20.000 sueldos que recibe Leonor y los 10.000 que van a las hijas de Juan. 
ros. Acaso uno de los momentos más duros fuera la condena inquisitorial post mortem de su suegro (1582) y el posterior desenterramiento de sus restos, que reposaban en la iglesia de los predicadores. El documento del Santo Oficio es de una dureza sin límites y fue leído, y expuesto durante tres días, en la iglesia de San Lorenzo, donde acudía la familia y de la que el condenado había sido presidente de los parroquianos años atrás. Pocos meses después eran ejecutados su suegra y un cuñado, y condenados a galeras su marido y dos de sus cuñados (junio 1583). Tras estos hechos, hay un silencio documental que dura dos años, en que María Albariel y los Çafar parecen haber sido tragados por la tierra, pero se explica porque María estaba cumpliendo una condena de tres años dictada en el auto de fe de 1582, y la administración de la hacienda corría a cargo del mercader Jaime de Aranda.

Que el matrimonio de su hija estaba planteado desde tiempo, lo podemos ver en un documento hecho en la Aljafería por Gabriel Çafar tras ser apresado al fugarse de galeras y antes de ser embarcado de nuevo. En esa escritura, Gabriel da poderes especiales a María para hacer las capitulaciones matrimoniales de Esperanza, cuando no era más que una niña de siete años. Ya en aquel momento la Real Audiencia había reconocido los derechos de sus hijos a la herencia de los Çafar. A partir de ese momento, la actividad de María se hace patente: vende albaranes de gran valor (hasta de 40.000 sueldos), recibe del administrador algunas piezas de oro y de plata de lo que había sido el tesoro de la familia y del que apenas vuelve a haber noticia, recupera los libros de cuentas y los inventarios hechos por la Inquisición, hace algunos préstamos, cobra algunas deudas, como la del concejo de Novales (que montaba a 18.960 sueldos) y también paga deudas de la familia, como la 3. ${ }^{a}$ parte de las rentas de Novales, Albero y Piracés que debía Jerónimo Çafar a su socio en el arriendo, Pedro Soria. Todo ello desde mayo a noviembre de 1585. No cabe duda de que la sentencia de la Real Audiencia puso en marcha a una mujer audaz, capaz de defender lo que le había llegado de los Çafar, lo que la obligó a recurrir a partir de ese momento a numerosos procuradores, entre ellos algún noble, como don Juan de Mendoza, que pudieran actuar en toda la geografía regional, porque por todo el territorio tenía María intereses y no le iba a resultar fácil recuperar lo que se había dejado de pagar a la familia en esos años de oscuridad que fueron los inmediatamente posteriores a las condenas de la Inquisición. Así, entre 1587 y 1589, la vemos pleitear con veintiún vecinos de Almudévar por una deuda de 21.000 sueldos $^{12}$, contra el concejo de Antillón para cobrar unas comandas hechas por Jerónimo y su hermano Hernando; lleva acciones legales contra algún noble que se negaba a respetar contratos hechos con los desaparecidos Çafar, como

12. María Albariel es acusada de deber 21.000 sueldos a un número indeterminado de vecinos de Almudévar, y 138 libras a los herederos del racionero de la seo Miguel de Piracés. 
es Juan Gómez, señor de Garasa, y contra el señor de Bureta por una deuda de 13.000 sueldos; actúa contra su cuñado José, quien por medio de un representante le reclamaba 3.000 sueldos de una deuda adquirida en galeras y que ella se negó a pagar alegando no tener bienes de José, cosa que más adelante se demostrará que es falso, porque en noviembre de 1589 vemos cómo José vende el granero heredado de su hermano Hernando y que había estado bajo control de Albariel. También María firma paces y renuncias en nombre de sus hijos a cualquier derecho ya extinguido de viejos arrendamientos, como con Francisca Ximénez, señora de Castejón y de Arbaniés. Y recibe de sus hijos, en abril de 1589, 21.000 sueldos y algunos bienes que le correspondían por testamento de Hernando Çafar, padre e hijo, y de Esperanza Compás. Una de las operaciones más importantes es la comanda de 120.000 sueldos dada por Esperanza a su hermano Hernando, que nos indica que en aquellos momentos, antes del matrimonio con Juan Felices, la economía de los Çafar no había entrado en su decadencia final, lo que justifícaría el interés del pequeño noble en un matrimonio muy ventajoso para él, a pesar de que, socialmente, sería difícil aceptar esa unión con una nieta de relajados e hija de condenados por la Inquisición.

Aparte del enfrentamiento con José, del que ya se ha hablado, María Albariel mantuvo otro con su cuñada Cándida Compañero, madre de Juanico, quien de no morir hubiera heredado toda la fortuna familiar. Cándida vivió un tiempo en Logroño, y por medio de su pariente Miguel Enrique Compañero reclama lo que creía que le correspondía de los testamentos de su marido, de sus suegros y de su cuñado Hernando, un total de 80.000 sueldos y un censo de 10.000 sueldos. El proceso, iniciado en 1586, aún dura en 1589, cuando la reclamación la hacen los herederos de Cándida. Ni ella ni sus sucesores lograron que María Albariel les diera sino una pequeña compensación, arguyendo que la Real Audiencia reconoció los derechos plenos de sus hijos, los únicos herederos.

Casi lo mismo ocurre con José Çafar, que se consideraba, por testamentos de sus padres y hermanos, con derecho a recibir las casas de Peraltilla, un total de 70.000 sueldos y varias piezas de plata y oro. Por el fallo dado por el Justicia de Huesca en 1589 ha de conformarse con 20.000 sueldos y 10.000 sueldos de una deuda contraída por Pedro Arañón al comprar un granero del que luego se hablará, más 10.000 sueldos de la venta de los bienes de Peraltilla, que se había de hacer antes de ocho meses después del fallo.

No cabe duda de que María Albariel sola, y con su yerno tras el matrimonio de su hija, supo defender los intereses de ésta, pero también es probable que los recursos económicos de la familia estuvieran ya disminuidos y no pudiera hacerse frente a tantas deudas, lo que explicaría la venta de tres casas en Zaragoza propiedad de María Albariel el mismo año en que tuvo lugar el litigio con José Çafar y en que se lleva a efecto el matrimonio de su hija. 


\section{UN MATRIMONIO POR INTERÉS}

Lo que se pretendía con el enlace de Esperanza Çafar con Juan Felices tiene tanto una dimensión social como económica, y lo que movía a María Albariel y a Felices a concertar el matrimonio se complementaba. Juan, aun que perteneciente a la pequeña nobleza, no era rico, como lo demuestran los testamentos de su padre hechos a comienzos del siglo XVII, en que a él le deja 8.000 sueldos (1600) y en otro de 1601, ni eso, sólo 10.000 sueldos a repartir entre sus tres hijas que únicamente se harían efectivos si casaban o profesaban en un convento. Muy poco, comparado con lo que sabemos que aporta Esperanza en el momento de las capitulaciones, de manera que Juan Felices daba un verdadero braguetazo, a pesar de que sabemos con certeza que ya en aquellos momentos la riqueza de los Çafar está muy disminuida e incluso, según se hace notar en las capitulaciones matrimoniales, los bienes familiares están aprehendidos por los Jurados de la ciudad, seguramente a causa de algunas deudas no satisfechas y a instancia de doña María de Mendoza. Felices, sin duda, estaba movido exclusivamente por intereses económicos, difícilmente podría estar enamorado de una niña de once años. Y esa ambición le hizo superar el temor que a un cristiano viejo debía darle el casarse con una conversa cuya familia había sido cruelmente marcada por la Inquisición. No es difícil pensar que carecía de escrúpulos, y en años posteriores veremos cómo esa personalidad queda patente al dejar en la ruina más absoluta a su familia. Resulta difícil imaginar a un infanzón metido a mercader y especulador, y así les fueron las cosas, aunque se aventuró en una sola acción de arriendo (o al menos no hay otro dato documental), concretamente el del onceno de la villa de Almudévar.

Para María Albariel, el matrimonio de su hija con un infanzón suponía una garantía para la conservación de lo que restaba del patrimonio, que pasaba a estar en manos cristianas, y, a la vez, un ascenso social, ya que la ennoblecía. Era una vieja aspiración de numerosos moriscos, como ya manifestó Hernando Çafar mayor al ordenar en un testamento cerrado, de 1559, anulado por otros posteriores en los que no aparecía la cláusula, que si sus hijos querían heredar debían casarse con cristianas viejas ${ }^{13}$. Claro es que en aquel momento tenía miedo al Santo Oficio, por el que había pasado el año antes y que mantenía en prisión a su mujer. El matrimonio con Juan Felices será el que librará a Esperanza Çafar de la expulsión en 1611, como mujer de cristiano que era, aunque no pudo escapar, en 1612, a un duro juicio inquisi-

13. Esta cláusula es algo excepcional entre todos los testamentos de moriscos oscenses estudiados, acaso por eso el testamento se hizo cerrado y, además, nunca fue abierto, porque los posteriores lo anularon. Es seguro que la posibilidad de casar a su primogénito con su pariente Cándida Compañero, y así reforzar el poder económico, le hizo desistir de la pretensión de casar a sus hijos con cristianas viejas. 
torial en el que padeció varias sesiones de tormento, acusada de practicar el ramadán y de hacer gala de tener un tío en Argel y manifestar su intención de irse a vivir con él.

Las capitulaciones matrimoniales, hechas el 19 de julio de 1589 por María Albariel, con autorización de su marido y el consentimiento de su hijo, y Juan Felices, nos ponen en evidencia las diferencias económicas de ambos contrayentes. Pero, además, nos revelan que en aquel momento los bienes de los Çafar están aprehendidos y que los novios se comprometen a rescatarlos. No hay constancia de lo que en aquel momento tenían los Çafar, pero sí de lo que recibe Esperanza, además del impreciso "todos los bienes muebles e inmuebles" familiares. Su hermano le entrega en Huesca casas en la Pellería Vieja, un granero con corral, otro corral, cuatro portales en San Lorenzo, una viña en Los Tierços; un soto, un huerto y un mirador en el Campo del Toro y 2.000 sueldos de pensión de un censo de 40.000 s. de propiedad que debían las villas de Erla y Luna y otros lugares del duque de Villahermosa. María Albariel le entrega tres casas en la calle Doncellas de Zaragoza y sus bienes, valorados en 200.000 sueldos. Compensan a Hernando con 30.000 sueldos y dan a María Albariel 4.000 s. en el acto, además de $3.000 \mathrm{~s}$. anuales para ropa y caprichos, 2.000 sueldos anuales de por vida y $6.000 \mathrm{~s}$. cuando desee, además de mantenerla. Por contra, Juan no especifica lo que aporta al matrimonio, pero, sin duda, no alcanzarían el valor de lo que lleva Esperanza.

A partir de este momento, en todos los documentos vemos actuar a María Albariel conjuntamente con Juan Felices y Esperanza, a la que a veces se la llama alias Jasa. Quince días después de firmadas las capitulaciones, venden a Pedro Arañón un granero, con corral y bodega olearia, por el elevado precio de 16.000 sueldos, casi en la misma fecha en que José Çafar aparece en Huesca para arrendar unas casas en la Cruz de San Martín por 1.000 sueldos al año, heredadas de su padre. Ese año de 1589, como ya vimos, se presenta agitado para Esperanza y Juan, con algunos pleitos que les obligan a vender casas en Zaragoza.

1590 comienza con la entrega de los libros de cuentas a la Inquisición, a instancia de la morisca Gracia Ezcandar, de Zaragoza. No sabemos cuál podía ser el motivo, pero lo cierto es que se nos manifiesta que los bienes de los Çafar seguían, hasta no se sabe qué extremo, bajo control inquisitorial. Nunca más tendremos noticias de la contabilidad de la casa, pero la documentación nos demuestra a partir de este momento la crisis definitiva.

\section{EL DECLIVE}

Acaso el inicio del fin esté en la venta a Arañón del granero citado. En 1590, éste lo revende a la ciudad por 18.000 sueldos, y el asunto traerá cola, porque el año 1592 Miguel Enrique Compañero, residente en Borja, denuncia 
ante la justicia oscense a los tres vendedores y a su fianza, Miguel de Mendoza y Felices, por venta ilícita, apoyado por una cédula real emitida por Felipe II, en la que se reconoce el derecho de Compañero sobre los bienes transferidos en la venta. El litigio se complica por la reventa que había hecho Arañón a la ciudad, que acaba aprehendiendo bienes de los Çafar, que carecen de dinero en metálico para dar al concejo 18.000 sueldos. En 1596 aún duraba el asunto, y a instancias de Miguel Mendoza, la ciudad aprehende bienes de los Çafar: casas en Alquibla, tres casas más en el barrio morisco, un granero junto a la Cruz de San Martín, un huerto en Camino del Ibón y un corral en El Público. Este hecho, juntamente con las compensaciones económicas a José Çafar y a Cándida Compañero y sus herederos, ya citadas, debió descalabrar la economía de la familia.

La desintegración del patrimonio es evidente, y a ello contribuye también el regreso de galeras de Gabriel Çafar, a quien su hija entrega tres casas en Zaragoza para que viva con su mujer, 10.000 sueldos y 200 sueldos y seis cahíces de trigo anualmente, todo ello de acuerdo con las capitulaciones matrimoniales. Un año después se deshacen de otra casa con tienda en Zaragoza, aunque siguen poniendo en alquiler algunos inmuebles en Huesca, si bien de renta muy baja, a la vez que venden algunos censos y albaranes de escaso monto. Todas las operaciones realizadas en los años 90 y 91 son poco destacables, sean ventas, arriendos o, incluso, el cobro de viejas deudas contraídas con los Çafar, algunas de más de veinte años de antigüedad. Acaso haya dos excepciones: la permuta realizada con Juan de Almazor y Ana Bailo, por la que se deshacen de unas casas en el barrio de San Lorenzo y reciben una torre con tierras, campos, árboles y colmenas en la zona de Monzur y una comanda de 31.400 sueldos como garantía; y, en segundo lugar, el cobro de 5.637 sueldos que logran recuperar de una vieja comanda hecha por Hernando Çafar.

Las relaciones de Juan Felices con su suegro parece que se degradan, y en 1591 le retira la procuración que le había dado para que actuase en su nombre en la administración de los bienes que tenían en Zaragoza. No sabemos la causa del enfrentamiento, pero la figura de Juan Felices queda definida a partir de estos momentos en que, sin saber muy bien cómo y por qué, se endeuda de manera tal que acaba en la cárcel del común de Huesca, de donde lo sacan a caplienta el viejo administrador de la familia, Aranda, y el notario Sebastián Canales, después de pagar una fianza de 900 sueldos. No es de extrañar, de todos modos, que la mentalidad de un representante de la pequeña nobleza oscense estuviera muy lejos de la ideología de los Çafar, cuya capacidad para los negocios estaba más que demostrada, y que no estuviera a la altura de las circunstancias para llevar adelante los negocios familiares, que mientras María Albariel residió en Huesca estuvieron controlados por ella. Casi con toda seguridad, la enemistad entre Felices y sus suegros se debiera a dos maneras muy distintas de entender los asuntos económicos, aun- 
que la documentación no diga nada al respecto. Sí tenemos la certeza, sin embargo, de que Felices expulsó a su suegra de casa por cuestiones religiosas, según se desprende del juicio inquisitorial que padeció su mujer en $1612^{14}$.

Los años 1592 y 1593 dan poca información, y toda ella relacionada con préstamos tomados por Juan y Esperanza o venta de alguna comanda, lo que es indicativo de la mala situación por la que estaba pasando la familia, agravada por las dificultades que encuentran para poder cobrar censos, comandas y préstamos hechos por los Çafar. Para llevar a cabo esos cobros nombran procurador al alcaide de la cárcel de los manifestados del reino de Aragón, Antonio López Orós; sin embargo, no se observa en la documentación que surtiese efecto, y no hay constancia de que se llevara a cabo ni un solo cobro digno de consideración, ni siquiera recurriendo a la vía judicial, cosa que hacen en más de una ocasión, aunque ocasionalmente la justicia les da la razón y les permite cobrar obligaciones de algún concejo, como los 1.646 sueldos pagados por Liesa y los 1.480 de Pueyo de Fañanars el año 1595. La insolvencia económica conduce en 1594 a la aprehensión de una viña por la ciudad por orden de la Real Audiencia, viña posteriormente arrendada por Enrique Compañero. Aún se agrava más la situación por la reclamación hecha por Juan Compañero de unos albaranes por valor de 1.334 libras que fueron depositados en casa de Jerónimo Çafar, como procurador que era de Compañero, y también por el pago de 30.000 sueldos a Hernando Çafar, lo prometido en las capitulaciones matrimoniales de Juan y Esperanza.

La documentación posterior continúa con la misma tónica, y son numerosos los préstamos tomados por el matrimonio, a la vez que deben hacer frente a reclamaciones de antiguos acreedores de los Çafar. Entre todos los documentos destaca, no por el monto económico, sino por representar al colectivo de moriscos, la reclamación de 660 sueldos que en octubre de 1595 hacen los representantes de los conversos, que era una parte del dinero recaudado por Hernando y Jerónimo Çafar entre todos los moriscos de la ciudad de Huesca para pagar al Santo Oficio lo que estaban obligados a rendir anualmente, además de los $60 \mathrm{~s}$. que debía Esperanza al colectivo por ese concepto ${ }^{15}$. En el documento, del año 1595, aparecen relacionados catorce ca-

14. Concretamente, se la acusa de seguir el ramadán y de hacerlo seguir a su hija, lo que provocó una discusión entre el yerno y la suegra, que acaba viviendo en Zaragoza con su marido y sólo regresa a Huesca tras la muerte de Juan Felices.

15.

En el documento, del año 1595, aparecen relacionados catorce cabezas de familia que actúan en nombre del colectivo. Contrastan con los veintidós varones representantes de todos los conversos citados en 1554. Aunque no hay datos fiables sobre la población morisca de la ciudad de Huesca, todo invita a pensar que fue descendiendo a lo largo del siglo, acentuándose la pérdida de población a finales de siglo y comienzos del siguiente, cuando se observan numerosas ventas de patrimonio. Este proceso migratorio está, sin duda, relacionado con el acoso inquisitorial y con la amenaza de expulsión. De todos modos, a los catorce nombres 
bezas de familia, que contrastan con los veintidós representantes de otra escritura de 1554 . No hay muchos datos sobre el número de moriscos en la ciudad de Huesca, pero todo parece indicar que desde los finales del siglo XVI se da un movimiento migratorio notable.

El nivel de endeudamiento queda reflejado en el pleito que en 1597 inicia Miguel de Mendoza y Felices, primo de Juan, reclamándole 132 libras que había gastado para sacarlo de la cárcel de manifestados de Zaragoza ${ }^{16}$, donde estuvo preso el año 93, y para viático del viaje y otros gastos. Todos los testigos coinciden en que Mendoza tiene razón, pero, por lo visto, había actuado con demasiada buena fe y no se hizo documento alguno, por lo cual Felices no puede ser condenado. Los años finales del siglo siguen siendo parcos en información, y cuando hablan nos presentan un progresivo endeudamiento y rara vez un cobro, procedente normalmente de algún concejo, tal el caso de un nuevo pago de 1.092 sueldos por parte de Pueyo de Fañanars, obligado por sentencia arbitral, y 44 pares de gallinas del concejo de Argavieso, obligaciones que esos lugares tenían según los viejos arrendamientos hechos por los Çafar y que ya no estaban vigentes desde hacía muchos años.

En los finales de siglo y en los comienzos de la centuria siguiente, la documentación de los Çafar se hace cada vez más escasa, y toda ella nos demuestra un progresivo endeudamiento. Sin embargo, el carácter de Felices se nos manifiesta en su testamento, redactado en mayo de 1606, donde no hace mención alguna de sus deudas ni obliga a pagarlas, aspecto éste que siempre se tenía sumo cuidado en recoger en todos los testamentos. Por contra, se permite la fanfarronada de obligar a Esperanza a instituir un censal de 6.000 sueldos de propiedad para redimir cautivos. Por un documento de agosto, ya muerto Juan, sabemos que Esperanza se ve obligada a vender una escritura de recuperación de unas casas por valor de 7.000 sueldos y un trozo de patio por un precio notablemente inferior: 2.800 sueldos. Y lo justifica diciendo que no tiene dinero para pagar los 8.000 sueldos de deudas que dejó su marido. A partir de ese momento, Esperanza y su madre toman préstamos con frecuencia y venden algunos cobros pendientes, a fin de poder saldar alguna de las deudas de su marido, como la contraída con el concejo de Permisán, aunque para poder satisfacerla se ve obligada a pedir un préstamo de 1.800 sueldos al mismo concejo.

Esperanza no tenía dinero ni para reparar su casa, de manera que a la hora de hacer obras en el alero tiene que pedir un préstamo de 4.200 sueldos

recogidos en el documento de 1595 habría que añadir una decena más de cabezas de familia citados en otras escrituras del momento.

16. La cárcel de manifestados estaba destinada a quienes se habían "manifestado", es decir, acogido a la custodia del Justicia de Aragón a fin de evitar abusos de jueces o funcionarios. Si el justicia declaraba inocente al manifestado, salía en libertad; en caso contrario, pasaba a los jueces ordinarios. 
al Justicia y jurados de Huesca, al poco de morir su marido. El concejo sólo le da 3.000 sueldos a pagar en ocho años y con un interés de $150 \mathrm{~s}$. anuales. Este préstamo, y otro demandado al prior de San Pedro, además de algún pleito fallado en su contra ${ }^{17}$, la obligarán a vender en 1608 las casas grandes en las que vive, en el barrio de San Lorenzo; unas casicas en la Puerta de Zaragoza, un huerto que tiene arrendado y otros bienes sin especificar. Para efectuar la venta pide permiso al Justicia, porque es fideicomisaria de su marido, pero los bienes heredados debían pasar íntegramente a sus hijas. Un año más tarde, recibe de Guillén Ichart un préstamo de 12.000 sueldos, al tiempo que le vende al prestamista una casa en el Coso, junto a la que ella habita, por 6.500 sueldos $^{18}$.

Vale la pena detenerse en el detalle que acabamos de mencionar de la demanda de autorización para la venta de las casas en las que vivía, porque demuestra que no formaban parte de lo que ella aportó al matrimonio, sino que habían pertenecido a su marido. El testamento de Juan Felices es rotundo al respecto: toda su herencia la recibía su mujer, pero no podía deshacerse de ella. ¿Quiere decir que a Esperanza no le quedaba nada de su patrimonio propio con que hacer frente a un gasto de 3.000 sueldos? Pues así parece, porque de lo contrario no hubiese tenido problemas para vender o transferir los bienes. Mucho habían cambiado las cosas desde la época de máximo esplendor de la familia, cuando se movían cantidades de dinero realmente notables, e incluso desde las propias capitulaciones matrimoniales, en las que aparece una cláusula en la cual se dice que si al morir Juan los bienes de Esperanza superan los 200.000 sueldos, se repartirán a partes iguales entre Esperanza y los hijos del matrimonio.

Como puede observarse, la ruina había acabado con el antiguo poder de los Çafar, tal como demostraba también el inventario de bienes de Juan Felices hecho al poco de morir, que no tenía nada que ver con el realizado por la Inquisición en la casa de los Çafar el año 1582. Ahora, lo más notable son dos lienzos pequeños viejos representando el arca de Noé, algún candelabro, unos pocos muebles de nogal, alguna alfombra, unas pocas piezas de ropa de seda y lino con randas (a veces se indica que son viejas), unas colchas de colores, algún repostero, unos sillones de cuero y un salero de dos piezas y cuatro cucharillas de plata. Ni joyas, ni ropas de lujo, ni vajillas pre-

17. El pleito lo inicia María Albariel y los otros tutores de sus hijas, en 1607, exigiendo una deuda a varios vecinos de Almudévar del onceno que había arrendado su marido a Juan Gómez, pero éste dice que Felices tenía una deuda pendiente de pago de 400 sueldos, de manera que Albariel no consigue su propósito.

18. El documento recoge separadamente la venta y el préstamo, y no queda claro si Esperanza recibe los 12.000 sueldos del préstamo y los $6.500 \mathrm{~s}$. de la venta o sólo los 12.000 sueldos, que son consignados como comanda puro depósito. 
ciosas; el inventario de Felices nos denuncia una sobriedad que no era más que el fruto de la falta de recursos económicos.

En esos duros momentos, Esperanza cuenta con la compañía de su madre, que reside de nuevo en Huesca, donde permanecerá hasta el momento de la expulsión, si no murió antes. María Albariel, que había conocido y vivido los mejores momentos de la familia, es posible que ya viuda regresara a Huesca, y sin olvidar la vieja tradición familiar de participar en la aventura inversionista, en un intento de levantar la maltrecha economía familiar, arrienda en 1610 el trinquete de la ciudad, pero la operación no supone más que 400 sueldos de inversión, lo que deja a las claras cuál era la realidad.

Cuando en 1612 Esperanza es condenada por la Inquisición a pagar 50 ducados de oro es muy probable que se consumase ya el descalabro total, porque esa cantidad es muy elevada y resulta improbable que dispusiese de ella, al menos en efectivo, si consideramos cuál había sido la evolución de la economía de su familia y las pruebas más que evidentes de su hundimiento.

Lo ocurrido a partir de 1612 es, por el momento, desconocido, pero la investigación de nuevos protocolos notariales del Archivo de Huesca facilitará, sin duda, información sobre la última morisca residente en la ciudad, ejemplo magnífico de lo que fue el declive de la aristocracia morisca y el de toda la comunidad.

\section{BIBLIOGRAFÍA}

CONTE, A.: «La Inquisición y los Moriscos de la ciudad de Huesca», en Homenaje a D. Antonio Durán, Instituto de Estudios Altoaragoneses, Muesca, 1995.

- «La rama oscense de los Compañero», en Sharq al-Andalus, n. ${ }^{\circ}$ 13, Teruel-Alicante, 1996.

- «Nivel socioeconómico de los moriscos oscenses», actas del VII Simposio Internacional de Mudejarismo, Teruel, Centro de Estudios Mudéjares, IET, 1999.

\section{FUENTES ORIGINALES}

\section{ARCHIVO HistóRICO PROVINCIAL DE HUESCA}

Protocolos: 772, 1490, 790, 1051, (1558); 6 86, (1559); 738 (1560); 1125, 688 (1561); 689, 616 (1562); 718 (1563); 1135, 830 (1564); 690 (1565); 691, 618 (1566); 1140, 692, 1027, 869 (1567); 6034 (1568); 1129, 10356 (1569); 1130 (1570); 1138, 791 (1571); 1139, 694 (1572); 1141, 916, 838 (1574); 917, 835, 1142 (1575); 1101 (1576); 1102, 919, 953, 1144, 929, 686 (1577); 840, 930, 1030, 920 (1578); 931, 1146, 1031, 961 (1579); 1077, 962, 10359, 1351 1077, 899, 1032, 1227, 1078 (1580); 1351, 1078, 1148, 1105 (1581); 741, 8431102 (1582); 1018, 1149, 3830, 
930 (1585); 1186, 1077, 1017, 1084 (1586); 1060, 1017, 904, 1084, 1081, 2967 (1587); 1017, 1018, 1085, 905 (1589); 1018, 1086, 1179, 1156, 2928 (1589); 2928, 999, 1087 (1590); 740, 1018, 1492 (1591); 696, 740, 1064 (1592); 1107, (1593); 697, 1020, 1091 (1594); 698, 1092, 1194, 3001; 1195 (1596); 1195, 699, 1093 (1596); 1094 (1597); 1095 (1598); 1008, 1323 (1599); 1097, 1323 (1600); 1277 (1601); 2962 (1602); 704 (1603); 735 (1604); 1298, 3006, 3037, 2973, 736 (1606); 3007 (1607); 1045 (1608); 3009 (1609); 5968 (1510).

Justicia: 307/10 (1575); 8, fol. 35v (1576); 339/4 (1592); 354/15 (1597); 360/13 (1599); 384/1 (1605); 391/11 (1607); 391/1 (1608)

\section{ARCHIVO MUNICIPAL DE HUESCA}

Libros de Actas: 1556-57,1557-58.

\section{ARCHIVO CATEDRAL DE HUESCA}

Protocolos: A-108 (1589)

\section{ARChivo PARRoquial De SANTO DOMINGO DE HUESCA}

Libros de Bautismos I

\section{ARCHIVO PARROQUIAL DE SAN LORENZO DE HUESCA}

Libros de Bautismos I

\section{ARCHIVO HistóRICO DE PROTOCOLOS DE ZARAGOZA}

Protocolos: 2123 (1581); 471 (1582); 472, 564 (1583); 3830 (1585)

\section{ARCHIVO HISTÓRICO NACIONAL}

Inquisición: Libros 988 (1581); 989 (1582-83-85); 990 (1609); 991 (1612)

\section{RESUMEN}

La familia Çafar, junto a los Compañero, representan el grupo social más poderoso de los moriscos oscenses y con una mentalidad impregnada del capitalismo naciente. Sin embargo, tras las duras condenas inquisitoriales de 1582 y 1583 su fuerza va disminuyendo hasta quedar reducida casi a 
la nada. El intento de salvar la hacienda y la honra familiares por medio del matrimonio de la niña Esperanza Çafar con el infanzón Juan de Felices resultó en vano, a lo que, sin duda, contribuyó notablemente la mentalidad de Felices, incapaz de continuar con la actividad comercial de los Çafar.

\section{ABSTRACT}

The decadence of the Moorish aristocracy: the Çafar from Huesca case. The Çafar and the 'Compañero' families represent the most powerful social group of the Moorish from Huesca with a mentality full of the nascent capitalism. However, after the hard inquisitorial condemnations of 1582 and 1583, their force carne, gradually, down next to nothing. The attempt of saving the property and the family honour, marrying the girl Esperanza Çafar to the 'infanzón' Juan de Felices was in vain. Because, without a doubt, Felices did not have that mentality and was unable to continue with the commercial activity of the Çafar.

\section{NOTA}

Estando ya en prensa este artículo, he encontrado cuatro documentos relacionados con Esperanza Çafar y sus hijas que por su importancia vale la pena reseñar. Dos son de noviembre de 1612 (AHPH, Pr. 3012, fol. 592v-593r) y los otros de septiembre de 1613 (AHPH, Pr. 1281, fol. 106v-113r).

Las dos escrituras de 1612 nos manifiestan que Esperanza Çafar arrendaba dos casas suyas en Huesca al mercader Juan Poinzot por el tiempo de dos años. No sabemos qué casas eran, porque no se da la localización. En aquellos momentos, Esperanza es vecina de Huesca. Los documentos de 1613 nos informan de que Esperanza es vecina de Zaragoza. Así que entre una y otra fecha, trasladó su residencia a la ciudad del Ebro.

No sabemos cuál pudo ser la causa, pero no es aventurado relacionarla con su paso por el tribunal del Santo Oficio y con la muerte de su suegro, Juan Felices. No cabe duda de que en una ciudad pequeña como Huesca, en la que los Çafar habían sido muy conocidos, Esperanza y sus hijas se sentirían incómodas, especialmente por la muerte de Juan Felices, personaje de cierta influencia en el mundo oscense y que podría defenderlas de la animadversión que había conducido a la última Çafar ante la Inquisición.

Los dos documentos de 1613 están hechos por Juan Felices el mismo día. En el primero, su testamento último, deja a sus nietas solamente la legítima (20 sueldos a cada una) y 3.000 sueldos si casan o entran en religión, cumpliendo una manda del testamento de su mujer Ana de Baraiz. Pero es el otro documento el que realmente nos interesa. Y ello por dos razones; la primera, porque nos demuestra que Esperanza está ya viviendo en Zaragoza; la 
otra, porque certifica que Juan Felices le había hecho una comanda de 120.000 sueldos, cantidad realmente extraordinaria. No sabemos por qué y cuándo se hizo la comanda, pero tanto dinero resulta difícil de justificar si Esperanza Çafar no tuviera bienes con los que responder. De manera que, aparte de las casas de Huesca que arrienda, es probable que la Çafar tuviese bienes en Zaragoza. El documento de esta comanda es vendido por Juan Felices, y Esperanza se compromete a respetarlo y a mantener sus obligaciones con el nuevo propietario. Quizás futuros hallazgos den más luz al asunto. De momento, lo que interesa es que los últimos descendientes de los moriscos residentes en Huesca desaparecen de la ciudad y con su emigración podemos dar por concluida la historia de la comunidad musulmana oscense. 